NASA/TM-2003-212663

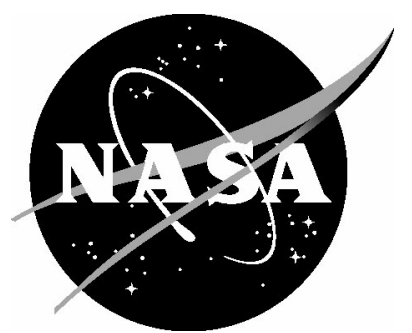

Failure Criteria for FRP Laminates in Plane Stress

Carlos G. Dávila

Langley Research Center, Hampton, Virginia

Pedro P. Camanho

University of Porto, Porto, Portugal 
Since its founding, NASA has been dedicated to the advancement of aeronautics and space science. The NASA Scientific and Technical Information (STI) Program Office plays a key part in helping NASA maintain this important role.

The NASA STI Program Office is operated by Langley Research Center, the lead center for NASA's scientific and technical information. The NASA STI Program Office provides access to the NASA STI Database, the largest collection of aeronautical and space science STI in the world. The Program Office is also NASA's institutional mechanism for disseminating the results of its research and development activities. These results are published by NASA in the NASA STI Report Series, which includes the following report types:

- TECHNICAL PUBLICATION. Reports of completed research or a major significant phase of research that present the results of NASA programs and include extensive data or theoretical analysis. Includes compilations of significant scientific and technical data and information deemed to be of continuing reference value. NASA counterpart of peerreviewed formal professional papers, but having less stringent limitations on manuscript length and extent of graphic presentations.

- TECHNICAL MEMORANDUM. Scientific and technical findings that are preliminary or of specialized interest, e.g., quick release reports, working papers, and bibliographies that contain minimal annotation. Does not contain extensive analysis.

- CONTRACTOR REPORT. Scientific and technical findings by NASA-sponsored contractors and grantees.
- CONFERENCE PUBLICATION. Collected papers from scientific and technical conferences, symposia, seminars, or other meetings sponsored or co-sponsored by NASA.

- SPECIAL PUBLICATION. Scientific, technical, or historical information from NASA programs, projects, and missions, often concerned with subjects having substantial public interest.

- TECHNICAL TRANSLATION. Englishlanguage translations of foreign scientific and technical material pertinent to NASA's mission.

Specialized services that complement the STI Program Office's diverse offerings include creating custom thesauri, building customized databases, organizing and publishing research results ... even providing videos.

For more information about the NASA STI Program Office, see the following:

- Access the NASA STI Program Home Page at http://www.sti.nasa.gov

- E-mail your question via the Internet to help@sti.nasa.gov

- Fax your question to the NASA STI Help Desk at (301) 621-0134

- Phone the NASA STI Help Desk at (301) 621-0390

- Write to:

NASA STI Help Desk

NASA Center for AeroSpace Information

7121 Standard Drive

Hanover, MD 21076-1320 
NASA/TM-2003-212663

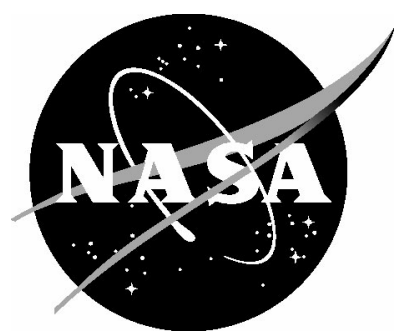

Failure Criteria for FRP Laminates in Plane Stress

Carlos G. Dávila

Langley Research Center, Hampton, Virginia

Pedro P. Camanho

University of Porto, Porto, Portugal

National Aeronautics and

Space Administration

Langley Research Center

Hampton, Virginia 23681-2199 
Available from:

NASA Center for AeroSpace Information (CASI)

7121 Standard Drive

Hanover, MD 21076-1320

(301) 621-0390
National Technical Information Service (NTIS) 5285 Port Royal Road Springfield, VA 22161-2171

(703) 605-6000 


\title{
FAILURE CRITERIA FOR FRP LAMINATES IN PLANE STRESS
}

\author{
Carlos G. Dávila and Pedro P. Camanho
}

\begin{abstract}
A new set of six failure criteria for fiber reinforced polymer laminates is described. Derived from Dvorak's fracture mechanics analyses of cracked plies and from Puck's action plane concept, the physically-based criteria, denoted LaRC03, predict matrix and fiber failure accurately without requiring curve-fitting parameters. For matrix failure under transverse compression, the fracture plane is calculated by maximizing the MohrCoulomb effective stresses. A criterion for fiber kinking is obtained by calculating the fiber misalignment under load, and applying the matrix failure criterion in the coordinate frame of the misalignment. Fracture mechanics models of matrix cracks are used to develop a criterion for matrix in tension and to calculate the associated in-situ strengths. The LaRC03 criteria are applied to a few examples to predict failure load envelopes and to predict the failure mode for each region of the envelope. The analysis results are compared to the predictions using other available failure criteria and with experimental results. Predictions obtained with LaRC03 correlate well with the experimental results.
\end{abstract}

\section{Introduction}

The aim of damage mechanics, the mathematical science dealing with quantitative descriptions of the physical events that alter a material when it is subjected to loads, is to develop a framework that describes the material response caused by the evolving damage state. The greatest difficulty in the development of an accurate and computationally efficient numerical procedure to predict damage growth has to do with how to analyze the material micro-structural changes and how to relate those changes to the material response. Several theories have been proposed for predicting failure of composites. Although significant progress has been made in this area, there is currently no single theory that accurately predicts failure at all levels of analysis, for all loading conditions, and for all types of fiber reinforced polymer (FRP) laminates. While some failure theories have a physical basis, most theories represent attempts to provide mathematical expressions that give a best fit of the available experimental data in a form that is practical from a designer's point of view.

To the structural engineer, failure criteria must be applicable at the level of the lamina, the laminate, and the structural component. Failure at these levels is often the consequence of an accumulation of micro-level failure events. Therefore, an understanding of micro-level failure mechanisms is necessary in order to develop accurate failure theories. 
The recent World Wide Failure Exercise ${ }^{1-7}$ (WWFE) conceived and conducted by Hinton and Soden provides a good assessment of the status of currently available theoretical methods for predicting material failure in fiber reinforced polymer composites. The recently published comparison of the predictions by the WWFE participants with experimental results indicates that even when analyzing simple laminates that have been studied extensively over the past 40 years, the predictions of most theories differ significantly from the experimental observations ${ }^{3}$.

The uncertainty in the prediction of initiation and progression of damage in composites has led to the undertaking of an effort at the NASA Langley Research Center to revisit existing failure theories, assess their capabilities, and to develop new theories where necessary. The present paper describes a newly developed set of six nonempirical criteria for predicting failure of unidirectional FRP laminates. All of the calculations presented are at the lamina level with plane stress assumptions. First, the motivation for non-empirical failure criteria for matrix shear and transverse tension and compression is established by examining several existing criteria. Next, new matrix failure criteria for matrix tension and compression are proposed. Then, a new fiber kinking failure criterion for fiber compression is developed by applying the matrix failure criteria to the configuration of the kink. The resulting set of six failure criteria is denoted LaRC03 and are summarized in the Appendix. Finally, some examples of failure envelopes are presented. The predicted results are compared to the results of other available failure criteria and with experimental results.

\section{Strength-Based Failure Criteria}

Strength-based failure criteria are commonly used with the finite element method to predict failure events in composite structures. A large number of continuum-based criteria have been derived to relate internal stresses and experimental measures of material strength to the onset of failure. One detailed discussion on the failure criteria proposed by Hashin, Puck, Sun and several others has been presented by París. ${ }^{8}$ París also discusses the ad hoc nature of the formulation of most strength-based criteria. In the following sections, the Hashin criteria ${ }^{9,10}$ are briefly reviewed, and improvements proposed by Sun $^{11}$ and Puck $^{5,6}$ over Hashin's theories are examined.

\section{Hashin Criteria 2D (1980)}

Hashin established the need for failure criteria that are based on failure mechanisms. In his 1973 proposal, he used his experimental observations of failure of tensile specimens to propose two different failure criteria, one related to fiber failure and the other related to matrix failure. The criteria assume a quadratic interaction between the tractions acting on the plane of failure. In 1980, he introduced fiber and matrix failure criteria that distinguish between tension and compression failure. Given the difficulty in obtaining the plane of fracture for the matrix compression mode, Hashin used a quadratic interaction between stress invariants. Such derivation was based on logical reasoning rather than micromechanics. Although the Hashin criteria were developed for unidirectional laminates, they have also been applied successfully to progressive failure analyses of laminates by using in-situ unidirectional strengths ${ }^{12}$ to account for the constraining interactions between the plies. The two-dimensional versions of the failure criteria proposed by Hashin in 1973 and 1980 are summarized in Table 1.

Numerous studies conducted over the past decade indicate that the stress interactions proposed by Hashin do not always fit the experimental results, especially in the case of matrix or fiber compression. It is well known, for instance, that moderate transverse compression $\left(\sigma_{22}<0\right)$ increase the apparent shear strength of a ply, which is not well predicted by Hashin's criterion. In addition, Hashin's fiber compression criterion does not account for the effects of in-plane shear, which reduce significantly the effective compressive strength of a ply. Several researchers have proposed modifications to Hashin's criteria to improve their predictive capabilities. Modifications proposed by Sun and Puck are described below. 


\section{Improved Criteria for Matrix Compression}

Sun et al. ${ }^{11}$ proposed an empirical modification to Hashin's 1973 criterion for matrix compression failure to take into account the beneficial role that compressive $\sigma_{22}$ has on matrix shear strength. The criterion is:

$$
\left(\frac{\sigma_{22}}{Y^{C}}\right)^{2}+\left(\frac{\tau_{12}}{S^{L}-\eta \sigma_{22}}\right)^{2}=1
$$

where $\eta$ is an experimentally determined constant and may be regarded as an internal material friction parameter. The denominator $S^{L}-\eta \sigma_{22}$ can be considered an effective longitudinal shear strength that increases with transverse compression $\sigma_{22}$ (see sign convention in Fig. 1). As in Hashin's theories, the angle of the fracture plane is not calculated.

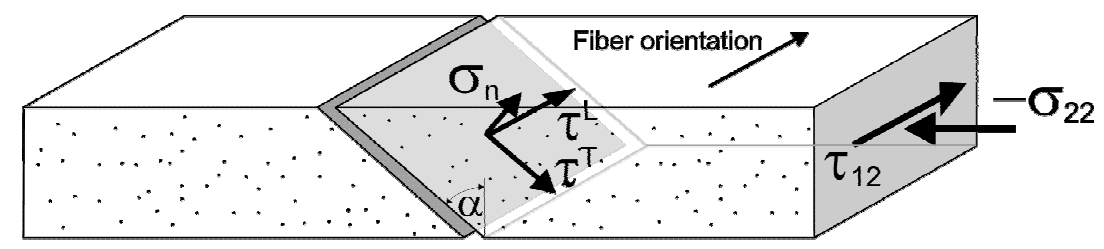

Figure 1. Fracture of a unidirectional lamina subjected to transverse compression and in-plane shear.

Table 1. Hashin Criteria ${ }^{9,10}$ for Plane Stress

\begin{tabular}{|l|l|l|}
\hline Matrix Failure & Matrix tension, $\sigma_{22} \geq 0$ & $\begin{array}{l}\text { Matrix compression, } \sigma_{22}<0 \\
1973: \quad F I_{M}=\left(\frac{\sigma_{22}}{Y^{C}}\right)^{2}+\left(\frac{\tau_{12}}{S^{L}}\right)^{2}\end{array}$ \\
& $F I_{M}=\left(\frac{\sigma_{22}}{Y^{T}}\right)^{2}+\left(\frac{\tau_{12}}{S^{L}}\right)^{2}$ & $1980: \quad F I_{M}=\left(\frac{\sigma_{22}}{2 S^{T}}\right)^{2}+\left[\left(\frac{Y^{C}}{2 S^{T}}\right)^{2}-1\right] \frac{\sigma_{22}}{Y^{C}}+\left(\frac{\tau_{12}}{S^{L}}\right)^{2}$ \\
\hline Fiber Failure & Fiber tension, $\sigma_{11} \geq 0$ & Fiber compression, $\sigma_{11}<0$ \\
& $F I_{F}=\left(\frac{\sigma_{11}}{X^{T}}\right)^{2}+\left(\frac{\tau_{12}}{S^{L}}\right)^{2}$ & $F I_{F}=\frac{\sigma_{11}}{X^{C}}$ \\
\hline
\end{tabular}

where,

$F I=$ Failure Index, where the subscripts $M$ and $F$ indicate matrix and fiber failure, respectively

$\sigma_{i j}=$ components of normal and shear stresses, with $i, j=1,2$

$X^{T}, X^{C}=$ strength in fiber direction under tension and compression, respectively (Longitudinal strength)

$Y^{T}, Y^{C}=$ strength normal to the fiber direction under tension and compression, respectively (Transverse strength)

$S^{L}$ and $S^{T}$ are the longitudial and transverse shear strengths, respectively.

Puck's Action Plane proposal ${ }^{5}$ represents the beneficial influence of transverse compression on matrix shear strength by increasing the shear strength by a term that is proportional to the normal stress $\sigma_{n}$ acting at the fracture plane shown in Fig. 1. In this formulation, the matrix failure criterion under transverse compression is: 


$$
\left(\frac{\tau^{T}}{S^{T}-\eta^{T} \sigma_{n}}\right)^{2}+\left(\frac{\tau^{L}}{S^{L}-\eta^{L} \sigma_{n}}\right)^{2}=1
$$

where $\tau^{T}$ and $\tau^{L}$ are the shear stresses acting on the fracture plane defined in Fig. 1. The direct contribution of $\sigma_{22}$ has been eliminated by assuming that the initiation of fracture is independent of the transverse compressive strength. Internal material friction is characterized by the coefficients $\eta^{L}$ and $\eta^{T}$, which are determined experimentally.

A key element to Puck's proposal is the calculation of the angle of the fracture plane, $\alpha$, shown in Fig. 1. Puck determined that matrix failures dominated by in-plane shear occur in a plane that is normal to the ply and parallel to the fibers $(\alpha=0)$. For increasing amounts of transverse compression, the angle of the fracture plane $\alpha$ changes to about $40^{\circ}$, and increases with compression to $53^{\circ} \pm 2^{\circ}$ for pure transverse compression. In the WWFE, Puck's predicted failure envelopes correlated very well with the test results. ${ }^{6}$ However, Puck's phenomenological approach uses several material parameters that are not physical and may be difficult to quantify without considerable experience with a particular material system.

\section{LaRC03 Criteria for Matrix Failure}

In this section, a new set of criteria is proposed for matrix fracture that is based on the concepts proposed by Hashin and the fracture plane concept proposed by Puck. In the case of matrix tension, the fracture planes are normal to the plane of the plies and parallel to the fiber direction. For matrix compression, the plane of fracture may not be normal to the ply, and Hashin was not able to calculate the angle of the plane of fracture. In the present proposal, Mohr-Coulomb effective stresses ${ }^{13}$ are used to calculate the angle of the fracture plane.

\section{Criterion for Matrix Failure Under Transverse Compression $\left(\sigma_{22} \leq 0\right)$}

The Mohr-Coulomb (M-C) criterion ${ }^{13}$ is commonly used in applications where fracture under tension loading is different from fracture under compression loading, such as in soil mechanics or in the fracture of cast iron. The application of the M-C criterion to multiaxial failure of epoxy resins was studied by Kawabata ${ }^{14}$ based on correlation with his own test results. While studying the failure of chopped glassfiber/epoxy mat laminates under confining pressures, Boehler ${ }^{15}$ found the Tsai-Wu criterion to be inadequate, and formulated a shearing criterion based on the $\mathrm{M}-\mathrm{C}$ criterion that fit his experimental measurements well. Taliercio ${ }^{16}$ used the $\mathrm{M}-\mathrm{C}$ criterion within a nonlinear micromechanical model to predict the macroscopic strength properties of fiber composites.

The M-C criterion is represented geometrically by the diagram illustrated in Fig. 2. The Mohr's circle represents a state of uniaxial compression. The angle of the plane of fracture $\alpha_{0}$ is set in this example at $53^{\circ}$, which is a typical fracture angle for composites under transverse compression loading $\left(\mathrm{Puck}^{5}\right)$. The line $\mathrm{AB}$ is the tangent to Mohr's circle at A and is called the Coulomb fracture line. The M-C criterion postulates that in a state of biaxial normal stress, fracture occurs for any Mohr's circle that is tangent to the Coulomb fracture line. The effective stress $\tau_{\text {eff }}$ is related to the stresses $\tau^{T}$ and $\sigma_{n}$ acting on the fracture plane by the expression $\tau_{\text {eff }}=\tau^{T}+\eta \sigma_{n}$. In the literature, $\tan ^{-1}(\eta)$ is called the angle of internal friction and it is assumed to be a material constant. When $\eta=0$, the $\mathrm{M}-\mathrm{C}$ criterion is equivalent to the Tresca condition ${ }^{13}$.

DiLandro ${ }^{17}$ explains the role of internal friction on the strength of carbon-fiber composites by noting the absence of chemical bonds between fiber and matrix, and that adhesion is attributed to Van der Waal's interactions. When subjected to an external load, the shear slipping of the two phases is prevented until the shear stress at the fiber-matrix interface reaches a limiting value. DiLandro also notes that $\eta$ is an empirical factor that encompasses all chemical-physical interactions, including the thermal residual 
shrinkage of the matrix around the fiber. Larson ${ }^{18}$ examined the relative effects of interfacial friction and roughness on the length of interfacial sliding which proceeds from the tip of an impinging fracture oriented perpendicular to the interface. According to Larson, sliding is key to the cracking behavior of fibrous brittle matrix composites in that it affects the stress concentration on the fibers, the matrix crack spacing, and, therefore, the global toughness of a composite material.

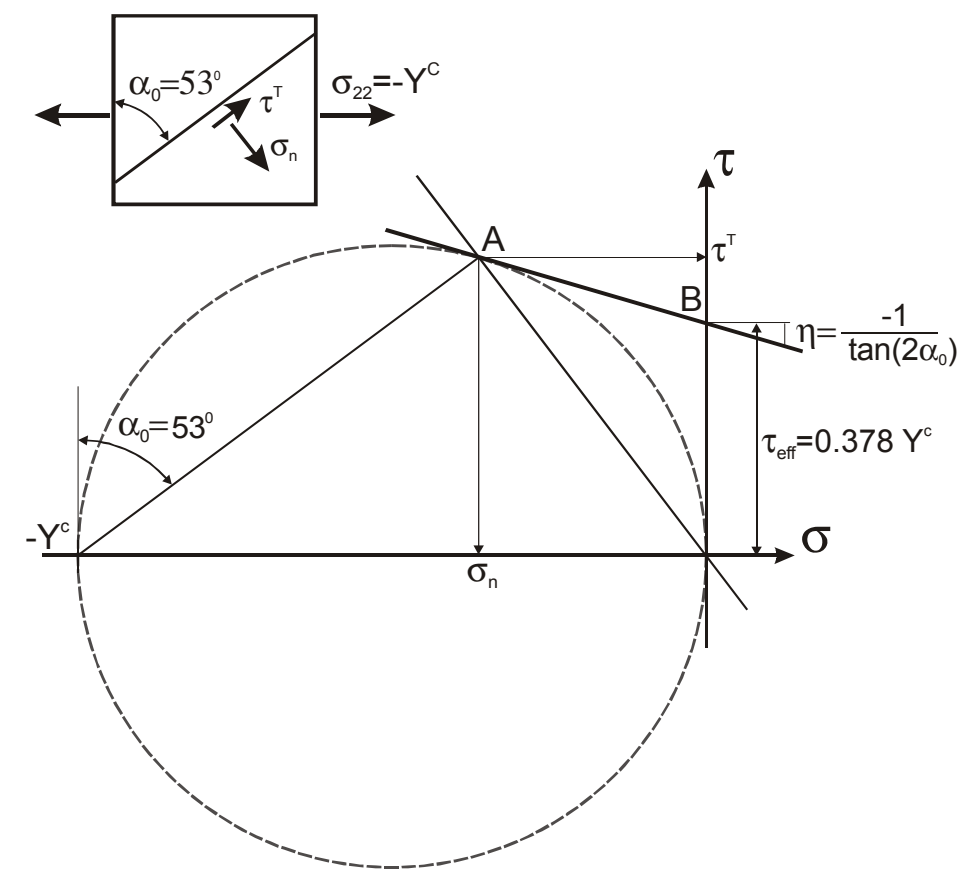

Figure 2. Mohr's circle for uniaxial compression and the effective transverse shear.

In general, the fracture plane can be subjected to transverse as well as in-plane stresses, in which case the effective stresses must be defined in both orthogonal directions as shown in Eq. 3 .

$$
\begin{aligned}
& \tau_{\text {eff }}^{T}=\left\langle\left|\tau^{T}\right|+\eta^{T} \sigma_{n}\right\rangle \\
& \tau_{e f f}^{L}=\left\langle\left|\tau^{L}\right|+\eta^{L} \sigma_{n}\right\rangle
\end{aligned}
$$

where the terms $\eta^{T}$ and $\eta^{L}$ are referred to as coefficients of transverse and longitudinal influence, respectively, and the operand $\langle x\rangle=x$ if $x \geq 0$; otherwise $\langle x\rangle=0$. Matrix failure under compression loading is assumed to result from a quadratic interaction between the effective shear stresses acting on the fracture plane. The failure index for a failure mode is written as an equality stating that stress states that violate the inequality are not physically admissible. The matrix failure index $\left(F I_{M}\right)$ is

LaRC03 \#1

$$
F I_{M}=\left(\frac{\tau_{e f f}^{T}}{S^{T}}\right)^{2}+\left(\frac{\tau_{e f f}^{L}}{S_{i s}^{L}}\right)^{2} \leq 1
$$

where $S^{T}$ and $S_{i s}^{L}$ are the transverse and longitudinal shear strengths, respectively. The subscript $M$ indicates matrix failure. The subscript is indicates that for general laminates, the in-situ longitudinal shear strength rather than the strength of a unidirectional laminate should be used. The constraining effect of adjacent plies substantially increases the effective strength of a ply. It is assumed here that the 
transverse shear strength $S^{T}$ is not subjected to in-situ effects, which is an assumption that deserves to be studied further. The calculation of in-situ strength $S_{i s}^{L}$ is discussed in a later section of this paper.

The stress components acting on the fracture plane can be expressed in terms of the in-plane stresses and the angle of the fracture plane, $\alpha$ (see Fig. 1).

$$
\begin{aligned}
& \sigma_{n}=\cos ^{2} \alpha \sigma_{22} \\
& \tau^{T}=-\sin \alpha \cos \alpha \sigma_{22} \\
& \tau^{L}=\tau_{12} \cos \alpha
\end{aligned}
$$

Using Eqs. 3 and 5, the effective stresses for an angle of the fracture plane $\alpha$ between $0^{\circ}$ and $90^{\circ}$ are

$$
\begin{aligned}
& \tau_{\text {eff }}^{T}=\left\langle-\sigma_{22} \cos \alpha\left(\sin \alpha-\eta^{T} \cos \alpha\right)\right\rangle \\
& \tau_{\text {eff }}^{L}=\left\langle\cos \alpha\left(\left|\tau_{12}\right|+\eta^{L} \sigma_{22} \cos \alpha\right)\right\rangle
\end{aligned}
$$

\section{Calculation of Coefficients $\eta^{T}$ and $\eta^{L}$ and Strength $S^{T}$}

The coefficients of influence $\eta^{T}$ and $\eta^{L}$ are obtained from the case of uniaxial transverse compression $\left(\sigma_{22}<0, \tau_{12}=0\right)$. At failure, the in-plane compressive stress is equal to the matrix compressive strength, $\sigma_{22}=-Y^{C}$. The effective transverse shear stress at failure is

$$
\tau_{\text {eff }}^{T}=S^{T}=Y^{C} \cos \alpha\left(\sin \alpha-\eta^{T} \cos \alpha\right)
$$

Under uniaxial transverse compression, fracture occurs at a fracture angle $\alpha_{0}$ that maximizes the effective transverse shear. Taking the derivative of the transverse shear stress, Eq. 7, with respect to $\alpha$ gives

$$
\begin{aligned}
\frac{\partial \tau_{e f f}^{T}}{\partial \alpha} & =0=-\sin \alpha_{0}\left(\sin \alpha_{0}-\eta^{T} \cos \alpha_{0}\right)+\cos \alpha_{0}\left(\cos \alpha_{0}+\eta^{T} \sin \alpha_{0}\right) \\
& \Rightarrow \cos ^{2} \alpha_{0}-\sin ^{2} \alpha_{0}+2 \eta^{T} \sin \alpha_{0} \cos \alpha_{0}=0
\end{aligned}
$$

Solving Eq. 8 for $\eta^{T}$ gives

$$
\eta^{T}=\frac{-1}{\tan 2 \alpha_{0}}
$$

Puck $^{5}$ determined that when loaded in transverse compression, most unidirectional graphite/epoxy composites fail by transverse shear along a fracture plane oriented at $\alpha_{0}=53^{\circ} \pm 2^{\circ}$. Therefore, the coefficient of transverse influence is in the range $0.21 \leq \eta^{T} \leq 0.36$. Note that if the fracture plane were oriented at $\alpha_{0}=45^{\circ}$, the coefficient of transverse influence would be equal to zero.

The transverse shear strength $S^{T}$ is a material property that is difficult to measure experimentally. However, substituting Eq. 9 into Eq. 7 gives an expression relating the transverse shear strength to the transverse compressive strength:

$$
S^{T}=Y^{C} \cos \alpha_{0}\left(\sin \alpha_{0}+\frac{\cos \alpha_{0}}{\tan 2 \alpha_{0}}\right)
$$


For a typical fracture angle of $\alpha_{0}=53^{\circ}$ gives $S^{T}=0.378 Y^{C}$, as was shown in Fig. 2 . Note that in some textbooks, the transverse shear strength is often approximated as $S^{T}=0.5 Y^{C}$, which implies from Eqs. 7 and 9 that the fracture plane is at $\alpha_{0}=45^{\circ}$ and that $\eta^{T}=0$. Also note that with this approximation, Hashin's 1980 two-dimensional criterion for matrix failure in compression becomes identical to his 1973 criterion.

The coefficient of longitudinal influence, $\eta^{L}$, can be determined from shear tests with varying degrees of transverse compression. In the absence of biaxial test data, $\eta^{L}$ can be estimated from the longitudinal and transverse shear strengths, as proposed by Puck:

$$
\begin{aligned}
& \frac{\eta^{L}}{S^{L}}=\frac{\eta^{T}}{S^{T}} \\
& \Rightarrow \eta^{L}=\frac{-S^{L}}{Y^{C} \cos \alpha_{0}\left(\tan 2 \alpha_{0} \sin \alpha_{0}+\cos \alpha_{0}\right)} \\
& \Rightarrow \eta^{L}=-\frac{S^{L} \cos 2 \alpha_{0}}{Y^{C} \cos ^{2} \alpha_{0}}
\end{aligned}
$$

\section{Determination of the Angle of the Fracture Plane}

The angle of the fracture plane for a unidirectional laminate loaded in transverse compression is a material property that is easily obtained from experimental data. However, under combined loads, the angle of the fracture plane is unknown. The correct angle of the fracture plane is the one that maximizes the failure index, $F I$, in Eq. 4. In the present work, the fracture angle is obtained by searching for the maximum of the failure index (Eq. 4) within a loop over the range of possible fracture angles: $0<\alpha<\alpha_{0}$. A graphical representation of matrix failure envelopes at various fracture angles is shown in Fig. 3 for a unidirectional E-Glass/LY556 composite subjected to transverse compression and in-plane shear. As seen in the figure, the fracture angle that maximizes the $F I$ for small transverse stresses is $\alpha=0^{\circ}$. When the applied transverse stress $\sigma_{22}$ has a magnitude equal to approximately $2 / 3$ of the transverse compressive strength, $Y^{C}$, the angle of the critical fracture plane switches from $\alpha=0^{\circ}$ to $\alpha=40^{\circ}$, and then rapidly increases to $\alpha=\alpha_{0}$, the angle of fracture for uniaxial transverse compression.

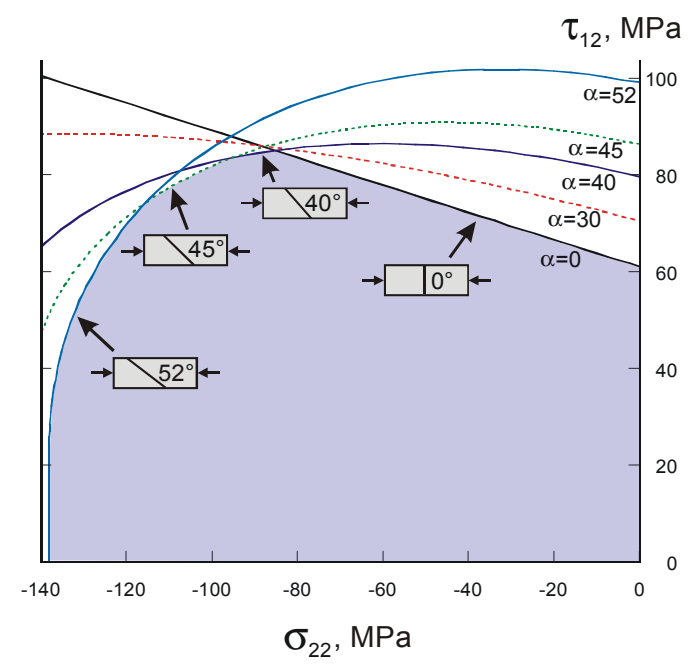

Figure 3. Matrix failure envelopes for a typical unidirectional E-glass/epoxy lamina subjected to inplane transverse compression and shear loading. 


\section{Criterion for Matrix Failure Under Transverse Tension $\left(\sigma_{22}>0\right)$}

A failure criterion to predict matrix cracking under the presence of both in-plane shear and transverse tensile stresses should represent the "in-situ" effect occurring in laminated composites. The in-situ effect, originally detected in Parvizi's ${ }^{19}$ tensile tests of cross-ply glass fiber reinforced plastics, is characterized by higher transverse tensile and shear strengths of a ply when it is constrained by plies with different fiber orientations in a laminate, when compared with the strength of the same ply in a unidirectional laminate. The in-situ strength also depends on the number of plies clustered together, and on the fiber orientation of the constraining plies.

The orientation of the constraining plies and the number of plies clustered together also affect the crack density and the stiffness reduction of the cracked ply. Wang's ${ }^{20}$ tests of $\left[0 / 90_{n} / 0\right] \quad(n=1,2,3,4)$ carbon/epoxy laminates have shown higher crack densities for thinner $90^{\circ}$ layers. The reduction of the elastic properties of a cracked ply is normally predicted using elastic analyses of cracked plies, ${ }^{12,21}$ or Continuum Damage Models. ${ }^{22-25}$

The in-situ effect is illustrated in Figure 4, where the relation between the in-situ transverse tensile strength and the total thickness of the $90^{\circ}$ plies clustered together is represented.

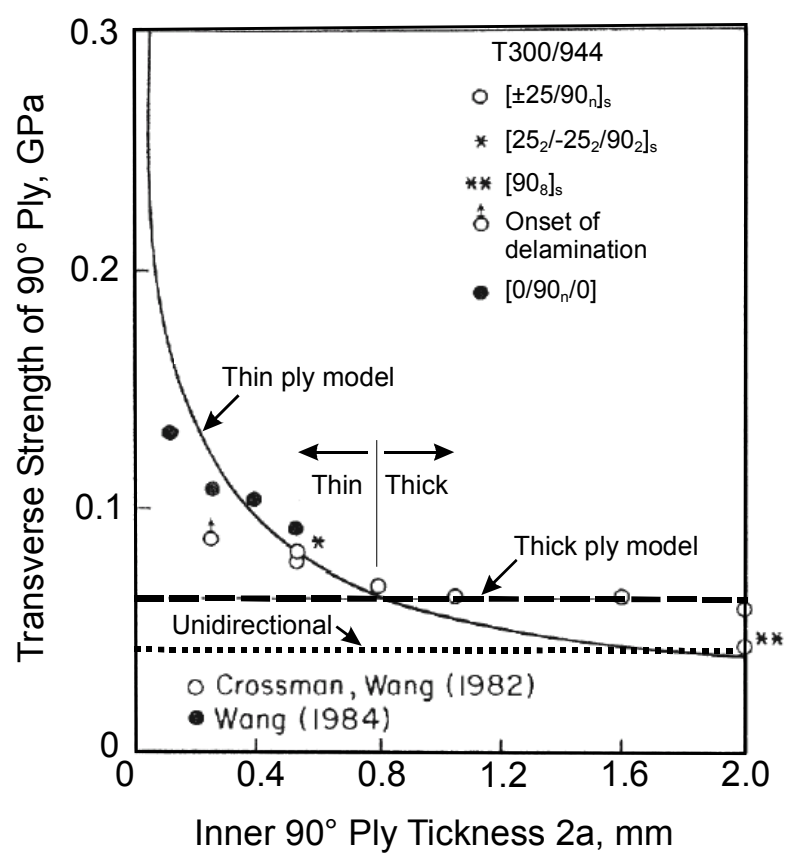

Figure 4. Transverse tensile strength as a function of number of plies clustered together, with models from Dvorak ${ }^{26}$ based on experimental data from Wang ${ }^{20}$.

Accurate in-situ strengths are necessary for any stress-based failure criterion for matrix cracking in constrained plies. Both experimental ${ }^{20,27,28}$ and analytical methods ${ }^{21,26,29}$ have been proposed to determine the in-situ strengths. In the following sections, the in-situ strengths are calculated using fracture mechanics solutions for the propagation of cracks in a constrained ply.

\section{Fracture Mechanics Analysis of a Cracked Ply}

The failure criterion for predicting matrix cracking in a ply subjected to in-plane shear and transverse tension proposed here is based on the fracture mechanics analysis of a slit crack in a ply, as proposed by Dvorak and Laws. ${ }^{26}$ The slit crack represents a manufacturing defect that is idealized as lying on the 1-3 
plane, as represented in Figure 5. It has a length $2 a_{0}$ across the thickness of a ply, $t$. Physically, this crack represents a distribution of matrix-fiber debonds that may be present in a ply as a consequence of manufacturing defects or from residual thermal stresses resulting from the different coefficients of thermal expansion of the fibers and of the matrix. Therefore, the slit crack is an "effective crack," representing the macroscopic effect of matrix-fiber debonds that occur at the micromechanical level. ${ }^{20}$
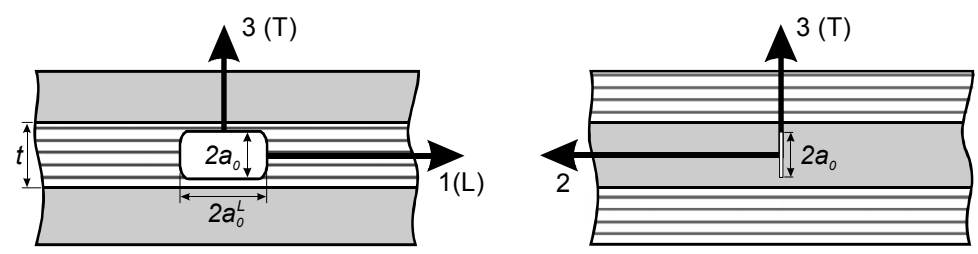

Figure 5. Slit crack geometry (after Dvorak $\left.{ }^{26}\right)$.

Plane stress conditions are assumed. The transverse tensile stress $\sigma_{22}$ is associated with mode I loading, whereas the in-plane shear stress $\sigma_{12}$ is associated with mode II loading. The crack represented in Fig. 5 can grow in the 1 (longitudinal, L) direction, in the 3 (transverse, T) direction, or in both directions.

The components of the energy release rate for the crack geometry represented in Fig. 5 were determined by Dvorak and Laws. ${ }^{26}$ For mixed-mode loading, the energy release rate for crack growth in the T and L directions, $G(T)$ and $G(L)$, respectively, are given by:

$$
\begin{aligned}
& G(T)=\frac{\pi a_{0}}{2}\left(\eta_{I}^{2} \Lambda_{22}^{0} \sigma_{22}^{2}+\eta_{I I}^{2} \Lambda_{44}^{0} \tau_{12}^{2}\right) \\
& G(L)=\frac{\pi a_{0}}{4}\left(\xi_{I}^{2} \Lambda_{22}^{0} \sigma_{22}^{2}+\xi_{I I}^{2} \Lambda_{44}^{0} \tau_{12}^{2}\right)
\end{aligned}
$$

where it can be observed that the energy release rate $G(L)$ for longitudinal propagation is a function of the transverse slit size $a_{0}$ and that it is not a function of the slit length in the longitudinal direction $a_{0}^{L}$.

The parameters $\eta_{\mathrm{i}}, i=I, I I$ in Eq. 12 are the stress intensity reduction coefficients for propagation in the transverse direction, and the parameters $\xi_{\mathrm{i}}, i=I, I I$ are the reduction coefficients for propagation in the longitudinal direction. These coefficients account for the constraining effects of the adjoining layers on crack propagation: the coefficients are nearly equal to 1.0 when $2 a_{0}<<t$, and are less than 1.0 when $a_{0} \approx t$. Experimental results ${ }^{28}$ have shown an increase in the in-situ transverse tensile strength of $\left[ \pm \theta / 90_{\mathrm{n}}\right]_{\mathrm{s}}$, $\theta=0^{\circ}, 30^{\circ}, 60^{\circ}$, laminates for increasing stiffness of adjoining sublaminates $\pm \theta$. This implies that the value of the parameter $\eta_{\mathrm{i}}$ decreases with increasing stiffness of adjoining sublaminates. Considering that a transverse crack can promote delamination between the plies, Dvorak and Laws ${ }^{26}$ suggested that the effective value of $\eta_{\mathrm{i}}$ can be larger than obtained from the analysis of cracks terminating at the interface, and suggested the use of $\eta_{\mathrm{i}}=\xi_{\mathrm{i}}=1$.

The parameters $\Lambda_{j j}^{0}$ are calculated as: ${ }^{26}$

$$
\begin{aligned}
& \Lambda_{22}^{0}=2\left(\frac{1}{E_{2}}-\frac{v_{21}^{2}}{E_{1}}\right) \\
& \Lambda_{44}^{0}=\frac{1}{G_{12}}
\end{aligned}
$$


The mode I and mode II components of the energy release rate can be obtained for the T-direction using Eq. (12) with $\eta_{\mathrm{i}}=1$ :

$$
\begin{aligned}
& G_{I}(T)=\frac{\pi a_{0}}{2} \Lambda_{22}^{0} \sigma_{22}^{2} \\
& G_{I I}(T)=\frac{\pi a_{0}}{2} \Lambda_{44}^{0} \tau_{12}^{2}
\end{aligned}
$$

The corresponding components of the fracture toughness are given as:

$$
\begin{aligned}
& G_{I c}(T)=\frac{\pi a_{0}}{2} \Lambda_{22}^{0}\left(Y_{i s}^{T}\right)^{2} \\
& G_{I I c}(T)=\frac{\pi a_{0}}{2} \Lambda_{44}^{0}\left(S_{i s}^{L}\right)^{2}
\end{aligned}
$$

where $Y_{i s}^{T}$ and $S_{i s}^{L}$ are the in-situ transverse tensile and shear strengths, respectively.

For propagation in the longitudinal direction, the mode I and mode II components of the energy release rate are:

$$
\begin{aligned}
& G_{I}(L)=\frac{\pi a_{0}}{4} \Lambda_{22}^{0} \sigma_{22}^{2} \\
& G_{I I}(L)=\frac{\pi a_{0}}{4} \Lambda_{44}^{0} \tau_{12}^{2}
\end{aligned}
$$

and the components of the fracture toughness are:

$$
\begin{aligned}
& G_{I c}(L)=\frac{\pi a_{0}}{4} \Lambda_{22}^{0}\left(Y_{i s}^{T}\right)^{2} \\
& G_{I I c}(L)=\frac{\pi a_{0}}{4} \Lambda_{44}^{0}\left(S_{i s}^{L}\right)^{2}
\end{aligned}
$$

Having obtained expressions for the components of the energy release rate and fracture toughness, a failure criterion can be applied to predict the propagation of the slit crack represented in Figure 5. Under the presence of both in-plane shear and transverse tension, the critical energy release rate $G_{c}$ depends on the combined effect of all microscopic energy absorbing mechanisms such as the creation of new fracture surface. Relying on microscopic examinations of the fracture surface, Hahn ${ }^{30}$ observed that the fracture surface topography strongly depends on the type of loading. With increasing proportion of the stress intensity factor $K_{I I}$, more hackles are observed in the matrix, thereby indicating more energy absorption associated with crack extension. Therefore, Hahn proposed a mixed mode criterion written as a firstorder polynomial in the stress intensity factors $K_{I}$ and $K_{I I}$. Written in terms of the mode I and mode II energy release rates, the Hahn criterion is

$$
(1-g) \sqrt{\frac{G_{I}(i)}{G_{I c}(i)}}+g \frac{G_{I}(i)}{G_{I c}(i)}+\frac{G_{I I}(i)}{G_{I I c}(i)}=1, \quad i=T, L
$$


where the material constant $g$ is defined identically from either Eq. 14 or 17 as:

$$
g=\frac{G_{I c}}{G_{I I c}}=\frac{\Lambda_{22}^{0}}{\Lambda_{44}^{0}}\left(\frac{Y_{i s}^{T}}{S_{i s}^{L}}\right)^{2}
$$

A failure index for matrix tension can be expressed in terms of the ply stresses and in-situ strengths $Y_{i s}^{T}$ and $S_{i s}^{L}$ by substituting either Eqs. $14-15$ or 16-17 into the criterion in Eq. 18 to get:

LaRC03 \#2

$$
F I_{M}=(1-g) \frac{\sigma_{22}}{Y_{i s}^{T}}+g\left(\frac{\sigma_{22}}{Y_{i s}^{T}}\right)^{2}+\left(\frac{\tau_{12}}{S_{i s}^{L}}\right)^{2} \leq 1
$$

The criterion presented in Eq. 20, with both linear and quadratic terms of the transverse normal stress and a quadratic term of the in-plane shear stress, is similar to the criteria proposed by $\mathrm{Hahn}^{30}$, $\mathrm{Liu}^{31}$ (for transverse tension and in-plane shear), and Puck ${ }^{5}$. In addition, if $g=1 \mathrm{Eq} .18$ reverts to the linear version of the criterion proposed by $\mathrm{Wu}$ and $\mathrm{Reuter}^{32}$ for the propagation of delamination in laminated composites:

$$
\frac{G_{I}}{G_{I c}}+\frac{G_{I I}}{G_{I I c}}=1
$$

Furthermore, using $g=1$, Eq. 20 reverts to the well-known Hashin criterion ${ }^{9}$ for transverse matrix cracking under both in-plane shear and transverse tension, where the ply strengths are replaced by the insitu strengths:

$$
F I_{M}=\left(\frac{\sigma_{22}}{Y_{i s}^{T}}\right)^{2}+\left(\frac{\tau_{12}}{S_{i s}^{L}}\right)^{2} \leq 1
$$

\section{Application to thick embedded plies}

A thick ply is defined as one in which the length of the slit crack is much smaller than the ply thickness, $2 a_{0}<t$, as illustrated in Figure 6. The minimum thickness for a thick ply depends on the material used. For E-glass/epoxy and carbon/epoxy laminates, Dvorak and Laws ${ }^{26}$ calculated the transition thickness between a thin and a thick ply to be approximately $0.7 \mathrm{~mm}$, or about 5 to 6 plies.

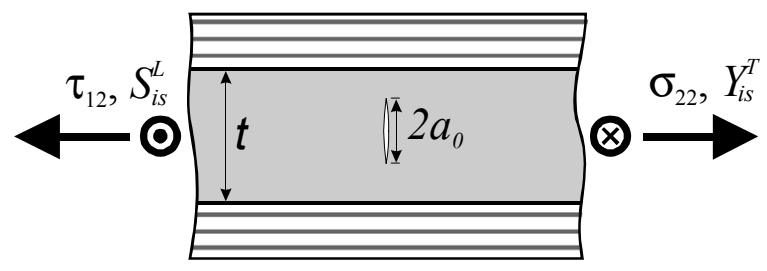

Figure 6. Geometry of slit crack in a thick embedded ply subjected to tension and shear loads. 
For the geometry represented in Fig. 6, the crack can grow in the transverse or in the longitudinal direction. Comparing Eqs. 14 and 16, however, indicates that the energy release rate for the crack slit is twice as large in the transverse direction as it is in the longitudinal direction. Since Eq. 14 also indicates that the energy release rate is proportional to the crack length $2 a_{0}$, the crack will grow unstably in the transverse direction. Once the crack reaches the constraining plies, it can propagate in the longitudinal direction, as well as induce a delamination.

Crack propagation is predicted using equation (20), and the in-situ strengths can be calculated from the components of the fracture toughness as:

$$
\begin{aligned}
& Y_{i s}^{T}=\sqrt{\frac{2 G_{I c}(T)}{\pi a_{0} \Lambda_{22}^{0}}} \\
& S_{i s}^{L}=\sqrt{\frac{2 G_{I I c}(T)}{\pi a_{0} \Lambda_{44}^{0}}}
\end{aligned}
$$

It can be observed from Eqs. 23 that the in-situ strengths of thick plies $Y_{i s}^{T}$ and $S_{i s}^{L}$ are functions of the toughnesses $G_{I c}(T)$ and $G_{I I c}(T)$ of the material and the size of the material flaw size, $2 a_{0}$. Therefore, the in-situ strengths for thick plies are independent of the ply thickness, as has been observed by Dvorak ${ }^{26}$ and Leguillon ${ }^{33}$, and as was shown in Fig. 4.

\section{Application to Thin Embedded Plies}

Thin plies are defined as having a thickness smaller than the typical defect, $t<2 a_{0}$, so the slit crack represented in Figure 5 extends across the entire thickness $t$ of the ply, as represented in Figure 7.

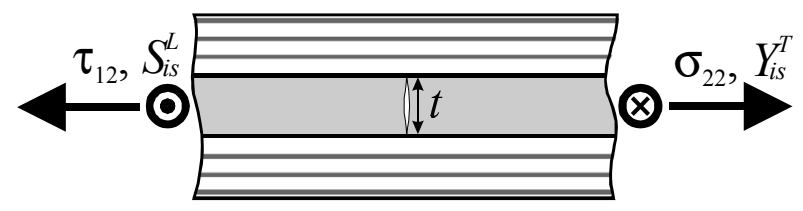

Figure 7. Geometry of slit crack in a thin embedded ply.

In the case of thin plies, crack defects can only grow in the longitudinal (L) direction, or trigger a delamination between the plies. The in-situ strengths can be calculated from the components of the fracture toughness as:

$$
\begin{aligned}
& Y_{i s}^{T}=\sqrt{\frac{8 G_{I c}(L)}{\pi t \Lambda_{22}^{0}}} \\
& S_{i s}^{L}=\sqrt{\frac{8 G_{I I c}(L)}{\pi t \Lambda_{44}^{0}}}
\end{aligned}
$$

where it can be observed that the in-situ strengths are inversely proportional to $\sqrt{t}$. The toughnesses $G_{I c}(L)$ and $G_{I I c}(L)$ can be assumed to be the values measured by standard Fracture Mechanics tests, such as the DCB for mode I and the ENF test for mode II. Using Eqs. 23 and 24, Dvorak and Laws ${ }^{26}$ 
obtained a good correlation between the predicted and experimentally obtained in-situ strengths of both thick and thin $90^{\circ}$ plies in $\left[0 / 90_{\mathrm{n}} / 0\right]$ laminates, as was shown in Fig. 4.

\section{Application to Unidirectional Laminates}

The fracture of a unidirectional specimen is taken as a particular case of a thick ply. ${ }^{26}$ The defect size is $2 a_{0}$, as for thick embedded plies. However, in the absence of constraining plies, the critical initial slit crack is located at the surface of the laminate. For tensile loading, the crack can be located at the edge of the laminate, which increases the energy release rate when compared with a central crack. In the case of shear loading, there is no free edge, so the crack is a central crack, as shown in Fig. 8. Crack propagation for unidirectional specimens subjected to tension or shear loads is obtained from the classic solution of the free edge crack. ${ }^{34}$
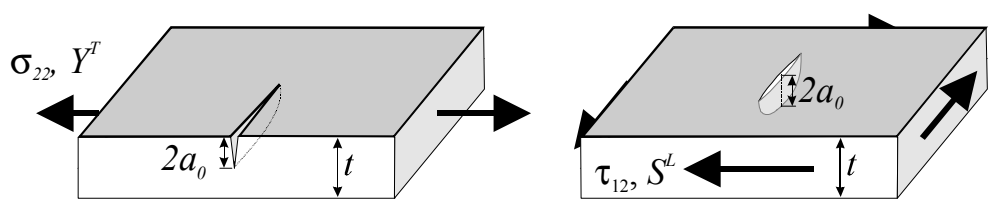

Figure 8. Unidirectional specimens under transverse tension and shear.

$$
\begin{aligned}
& G_{I c}(T)=1.12^{2} \pi a_{0} \Lambda_{22}^{0}\left(Y^{T}\right)^{2} \\
& G_{I I c}(T)=\pi a_{0} \Lambda_{44}^{0}\left(S^{L}\right)^{2}
\end{aligned}
$$

where $Y^{T}$ and $S^{L}$ are the material tensile and shear strengths as measured from unidirectional laminate tests. Note that the in-situ strengths for thick plies can be obtained as a function of the strength of unidirectional laminates by substituting Eqs. 25 into 23:

$$
\begin{aligned}
& Y_{i s}^{T}=1.12 \sqrt{2} Y^{T} \\
& S_{i s}^{L}=\sqrt{2} S^{L}
\end{aligned}
$$

The failure criterion for unidirectional plies under in-plane shear and transverse tension is represented in Eq. 20. The toughness ratio $g$ for a thick laminate can also be calculated in terms of the unidirectional properties by substituting Eqs. 25 into Eq. 19 to get:

$$
g=\frac{G_{I c}}{G_{I I c}}=1.12^{2} \frac{\Lambda_{22}^{0}}{\Lambda_{44}^{0}}\left(\frac{Y^{T}}{S^{L}}\right)^{2}
$$

\section{LaRC03 Criteria for Fiber Failure}

\section{Criterion for Fiber Tension Failure}

Based on the results of his experimental investigations, Puck ${ }^{5}$ recommends using a fiber failure criterion that is based on the "effective strain" acting along the fibers. However, Puck also reports that 
the difference between using the effective strain and the longitudinal stress is insignificant. ${ }^{6}$ The LaRC03 criterion for fiber tension failure is a non-interacting maximum allowable strain criterion that is simple to measure and is independent of fiber volume fraction and Young's moduli. Consequently, the LaRC03 failure index for fiber tensile failure is:

$$
\text { LaRC03 \#3 } F I_{F}=\frac{\varepsilon_{11}}{\varepsilon_{1}^{T}} \leq 1
$$

\section{Criterion for Fiber Compression Failure}

Compressive failure of aligned fiber composites occurs from the collapse of the fibers as a result of shear kinking and damage of the supporting matrix (See for instance the representative works of Fleck ${ }^{35}$ and Soutis ${ }^{36}$, and Shultheisz ${ }^{37}$ review of micromechanical compressive failure theories). Fiber kinking occurs as shear deformation leading to the formation of a kink band.

$\operatorname{Argon}^{38}$ was the first to analyze the kinking phenomenon. His analysis was based on the assumption of a local initial fiber misalignment. The fiber misalignment leads to shearing stresses between fibers that rotate the fibers, increasing the shearing stress and leading to instability. Since Argon's work, the calculation of the critical kinking stress has been significantly improved with a more complete understanding of the geometry of the kink band as well as the incorporation of friction and material nonlinearity in the analysis models. ${ }^{35-37,39}$

Several authors ${ }^{40,41}$ have considered that misaligned fibers fail by the formation of a kink band when local matrix cracking occurs. Potter et al. ${ }^{42}$ assumed that additional failure mechanisms that may occur under uniaxial longitudinal compression, such as crushing, brooming, and delaminations, are essentially triggered by matrix failure.

In the present approach, the compressive strength $X^{C}$ is assumed to be a known material property that can be used in the LaRC03 matrix damage criterion (Eq. 4) to calculate the fiber misalignment angle that would cause matrix failure under uniaxial compression.

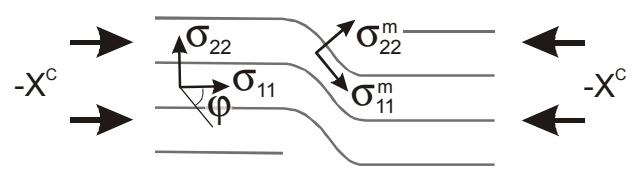

Figure 9. Imperfection in fiber alignment idealized as local region of waviness.

\section{Calculation of Fiber Misalignment Angle}

The imperfection in fiber alignment is idealized as a local region of waviness, as shown in Fig. 9. The ply stresses in the misalignment coordinate frame $m$ shown in Fig. 4 are

$$
\begin{array}{r}
\sigma_{11}^{m}=\cos ^{2} \varphi \sigma_{11}+\sin ^{2} \varphi \sigma_{22}+2 \sin \varphi \cos \varphi \tau_{12} \\
\sigma_{22}^{m}=\sin ^{2} \varphi \sigma_{11}+\cos ^{2} \varphi \sigma_{22}-2 \sin \varphi \cos \varphi \tau_{12} \\
\tau_{12}^{m}=-\sin \varphi \cos \varphi \sigma_{11}+\sin \varphi \cos \varphi \sigma_{22} \\
+\left(\cos ^{2} \varphi-\sin ^{2} \varphi\right) \tau_{12}
\end{array}
$$


At failure under axial compression, $\sigma_{11}=-X^{C}$, and $\sigma_{22}=\tau_{12}=0$. Substituting these values into Eq. 29 gives $\sigma_{22}^{m}=-\sin ^{2} \varphi^{C} X^{C}$ and $\tau_{12}^{m}=\sin \varphi^{C} \cos \varphi^{C} X^{C}$, where the angle $\varphi^{C}$ is the total misalignment angle for the case of axial compression loading only.

To calculate the failure index for fiber kinking, the stresses $\sigma_{22}^{m}$ and $\tau_{12}^{m}$ are substituted into the criterion for matrix compression failure (Eq. 4). The mode of failure in fiber kinking is dominated by the shear stress $\tau_{12}$, rather than by the transverse stress $\sigma_{22}$. The angle of the fracture plane is then equal to $0^{\circ}$, and $\tau_{\text {eff }}^{T}=0$. The matrix failure criterion becomes

$$
\tau_{e f f}^{L}=X^{C}\left(\sin \varphi^{C} \cos \varphi^{C}-\eta^{L} \sin ^{2} \varphi^{C}\right)=S_{i s}^{L}
$$

where $S_{i s}^{L}$ is the in-situ longitudinal shear strength defined in Eq. 23 for thick plies and in Eq. 24 for thin plies. Solving for $\varphi^{C}$ leads to the quadratic equation:

$$
\tan ^{2} \varphi^{C}\left(\frac{S_{i s}^{L}}{X^{C}}+\eta^{L}\right)-\tan \varphi^{C}+\left(\frac{S_{i s}^{L}}{X^{C}}\right)=0
$$

The smaller of the two roots of Eq. 31 is

$$
\varphi^{C}=\tan ^{-1}\left(\frac{1-\sqrt{1-4\left(\frac{S_{i s}^{L}}{X^{C}}+\eta^{L}\right)\left(\frac{S_{i s}^{L}}{X^{C}}\right)}}{2\left(\frac{S_{i s}^{L}}{X^{C}}+\eta^{L}\right)}\right)
$$

Note that if $\eta^{L}$ were neglected and $\varphi$ were assumed to be a small constant angle, Eq. 30 would give $\varphi^{C} \approx \frac{S_{i s}^{L}}{X^{C}}$, which is the expression derived by Argon $^{38}$ to estimate the fiber misalignment angle.

The total misalignment angle $\varphi$ can be decomposed into an initial (constant) misalignment angle $\varphi^{0}$ that represents a manufacturing imperfection, and an additional rotational component $\varphi^{R}$ that results from shear loading. The angles $\varphi^{0}$ and $\varphi^{R}$ can be calculated using small angle approximations and Eqs. 29

$$
\begin{aligned}
& \varphi^{R}=\frac{\tau_{12}^{m}}{G_{12}}=\frac{-\varphi \sigma_{11}+\varphi \sigma_{22}+\left|\tau_{12}\right|}{G_{12}} \\
& \varphi^{0}=\varphi^{C}-\left.\varphi^{R}\right|_{X^{C}}=\varphi^{C}-\left.\frac{\tau_{12}^{m}}{G_{12}}\right|_{X^{C}} \quad \Rightarrow \varphi^{0}=\varphi^{C}\left(1-\frac{X^{C}}{G_{12}}\right)
\end{aligned}
$$

where the absolute value of the shear $\left|\tau_{12}\right|$ is used because the sign of $\varphi$ is assumed to be positive, regardless of the sign of the shear stress. Recalling that $\varphi=\varphi^{0}+\varphi^{R}$, it is now possible to solve Eqs. 33 for $\varphi$ in terms of $\varphi^{C}$.

$$
\varphi=\frac{\left|\tau_{12}\right|+\left(G_{12}-X^{C}\right) \varphi^{C}}{G_{12}+\sigma_{11}-\sigma_{22}}
$$


Fiber compression failure by formation of a kink band is predicted using the stresses from Eq. 29 and the failure criterion for matrix tension or matrix compression. For matrix compression $\left(\sigma_{22}^{m}<0\right)$, the criterion is the Mohr-Coulomb criterion given in Eq. 4, with $\alpha=0^{\circ}$ and $\tau_{\text {eff }}^{T}=0$. The criterion for fiber kinking becomes:

LaRC03 \#4

$$
F I_{F}=\left\langle\frac{\left|\tau_{12}^{m}\right|+\eta^{L} \sigma_{22}^{m}}{S_{i s}^{L}}\right\rangle \leq 1
$$

For fiber compression with matrix tension, the transformed stresses of Eq. 29 are substituted into the matrix tensile failure criterion given in Eq. 20 to yield the following criterion for fiber kinking:

$$
\text { LaRC03 \#5 FI F }=(1-g)\left(\frac{\sigma_{22}^{m}}{Y_{i s}^{T}}\right)+g\left(\frac{\sigma_{22}^{m}}{Y_{i s}^{T}}\right)^{2}+\left(\frac{\tau_{12}^{m}}{S_{i s}^{L}}\right)^{2} \leq 1
$$

It is interesting to note that for $\sigma_{22}=0$, the fiber failure criterion in Eq. 35 becomes

$$
F I_{F}=\frac{-\sigma_{11}}{X^{C}}+\frac{\left|\tau_{12}\right|}{k S^{L}} \leq 1 \quad \text { with } \quad k=\frac{1}{1-\varphi^{2}-2 \eta^{L} \varphi}>1
$$

The linear interaction between $\sigma_{11}$ and $\tau_{12}$ in Eq. 37 is identical to the form used by Edge ${ }^{7}$ for the WWFE. For T300/914C, Edge suggests using an empirical value of $k=1.5$. However, Edge also indicates that other researchers have shown excellent correlation with experimental results with $k=1$. Using the WWFE strength values of $X^{C}=900 \mathrm{MPa}, S^{L}=80 \mathrm{MPa}, Y^{C}=200 \mathrm{MPa}$, an assumed fracture angle in transverse compression of $53^{\circ}$, and Eqs. 11 and 32, we get: $\eta^{L}=0.304, \varphi^{C}=5.3^{\circ}$. With the approximation $\varphi \cong \varphi^{C}$, Eq. 37 gives $k=1.07$.

\section{LaRC03 Criterion for Matrix Damage in Biaxial Compression}

In the presence of high transverse compression combined with moderate fiber compression, matrix damage can occur without the formation of kink bands or damage to the fibers. This matrix damage mode is calculated using the stresses in the misaligned frame in the failure criterion in Eq. 4, which gives:

$$
\text { LaRC03 \#6 } F I_{M}=\left(\frac{\tau_{e f f}^{m T}}{S^{T}}\right)^{2}+\left(\frac{\tau_{e f f}^{m L}}{S_{i s}^{L}}\right)^{2} \leq 1
$$

where the effective shear stresses $\tau_{e f f}^{m T}$ and $\tau_{\text {eff }}^{m L}$ are defined as in Eq. 6, but in terms of the in-plane stresses in the misalignement frame, which are defined in Eqs. 29.

$$
\begin{aligned}
\tau_{e f f}^{m T} & =\left\langle-\sigma_{22}^{m} \cos \alpha\left(\sin \alpha-\eta^{T} \cos \alpha\right)\right\rangle \\
\tau_{e f f}^{m L} & =\left\langle\cos \alpha\left(\left|\tau_{12}^{m}\right|+\eta^{L} \sigma_{22}^{m} \cos \alpha\right)\right\rangle
\end{aligned}
$$

As for all matrix compressive failures herein, the stresses $\tau_{e f f}^{m T}$ and $\tau_{e f f}^{m L}$ are functions of the fracture angle $\alpha$, which must be determined iteratively. 


\section{Verification Problems}

\section{Example 1. Unidirectional $0^{\circ}$ E-glass/MY750 epoxy}

All of the failure modes represented by the six LaRC03 criteria (Eqs. 4, 20, 28, 35, 36 and 38, and summarized in the Appendix) can be represented as a failure envelope in the $\sigma_{11}-\sigma_{22}$ plane. An example is shown in Fig. 10 for a $0^{\circ}$ E-glass/MY750 epoxy lamina. Puck's analysis results, which showed the best correlation with experimental results in the $\mathrm{WWFE}^{3}$, is also shown for comparison. In the figure, there is good agreement between LaRC03 and Puck in all quadrants except biaxial compression, where LaRC03 predicts an increase of the axial compressive strength with increasing transverse compression. Testing for biaxial loads presents a number of complexities, and experimental results are rare. However, Waas et al. ${ }^{43}$ report a number of references in which multiaxial compression was studied by superposing a hydrostatic pressure in addition to the compressive loading. For all materials considered, there is a significant increase in compressive strength with increasing pressure. In particular, the results of Wronsky and Parry ${ }^{44}$ on glass/epoxy show a strength increase of $3.3 \mathrm{MPa}$ per MPa of hydrostatic pressure, which gives an actual strength increase of 4.3 MPa per MPa of applied transverse biaxial stress. More recently, Sigley et al. ${ }^{45}$ found $32 \%$ to $71 \%$ increases in compressive strength per $100 \mathrm{MPa}$ superposed pressure. The results of Wronsky and Sigley can be compared qualitatively to the 4.3 $\mathrm{MPa} / \mathrm{MPa}$ increase in compressive strength for the plane stress failure envelope in Fig. 10.

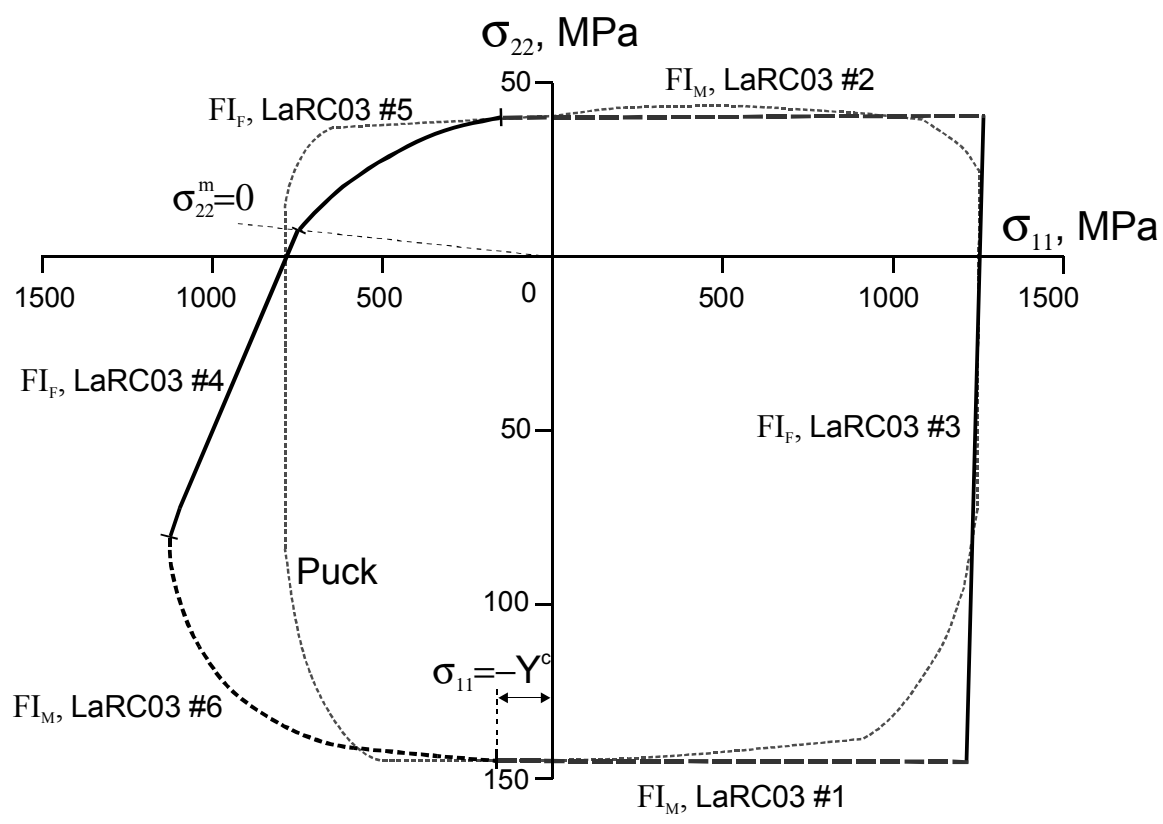

Figure 10. Biaxial $\sigma_{11}-\sigma_{22}$ failure envelope of $0^{\circ}$ E-glass/MY750 epoxy lamina.

\section{Example 2. Unidirectional composite E-Glass/LY556}

A comparison of results from various failure criteria with the experimental results in the $\sigma_{22}-\tau_{12}$ stress plane obtained from the WWFE ${ }^{46}$ is shown in Fig. 11. It can be observed that within the positive range of $\sigma_{22}$, all the quadratic failure criteria and LaRC03 give satisfactory results. Since the Maximum Stress criterion does not prescribe interactions between stress components, its failure envelope is rectangular. The most interesting behavior develops when $\sigma_{22}$ becomes compressive. Hashin's 1973 criterion gives an 
elliptical envelope with diminishing $\tau_{12}$ as the absolute value of compressive $\sigma_{22}$ increases, while the experimental data shows a definite trend of shear strength increase as $\sigma_{22}$ goes into compression.

The envelope for Hashin's 1980 criteria was calculated using a transverse strength obtained from Eq. 10 , and it provides a modest improvement in accuracy compared to the 1973 criterion. Of the criteria shown in Fig. 11, Sun (Eq. 1), LaRC03 \#1 (Eq. 4), and Puck (Eq. 2) capture the shear strength increase at the initial stage of compressive $\sigma_{22}$. The failure envelope for Sun's criterion (Eq. 1) was calculated using $\eta^{L}=0.336$ from Eq. 11. The results indicate a significant improvement over Hashin's criteria. An even better fit would have been achieved using a higher value for $\eta^{L}$. Puck's envelope, which was extracted from the $2002 \mathrm{WWFE}^{6}$, appears to be the most accurate, but it relies on fitting parameters based on the same test data. The LaRC03 curve uses the stiffnesses and strengths shown in Table 2, an assumed $\alpha_{0}=53^{\circ}$, and no other empirical or fitting parameter. In the case of matrix tension, Puck's predicted failure envelope is nearly identical to LaRC03 \#2.

Table 2. Properties of E-Glass/LY556 ${ }^{46}$ ( MPa)

\begin{tabular}{ccccccc}
\hline \hline $\boldsymbol{E}_{11}$ & $\boldsymbol{E}_{22}$ & $\boldsymbol{G}_{12}$ & $\boldsymbol{V}_{12}$ & $\boldsymbol{Y}^{\boldsymbol{T}}$ & $\boldsymbol{Y}^{\boldsymbol{C}}$ & $\boldsymbol{S}^{\boldsymbol{L}}$ \\
\hline 53,480 & 17,700 & 5,830 & 0.278 & 36 & 138 & 61 \\
\hline \hline
\end{tabular}

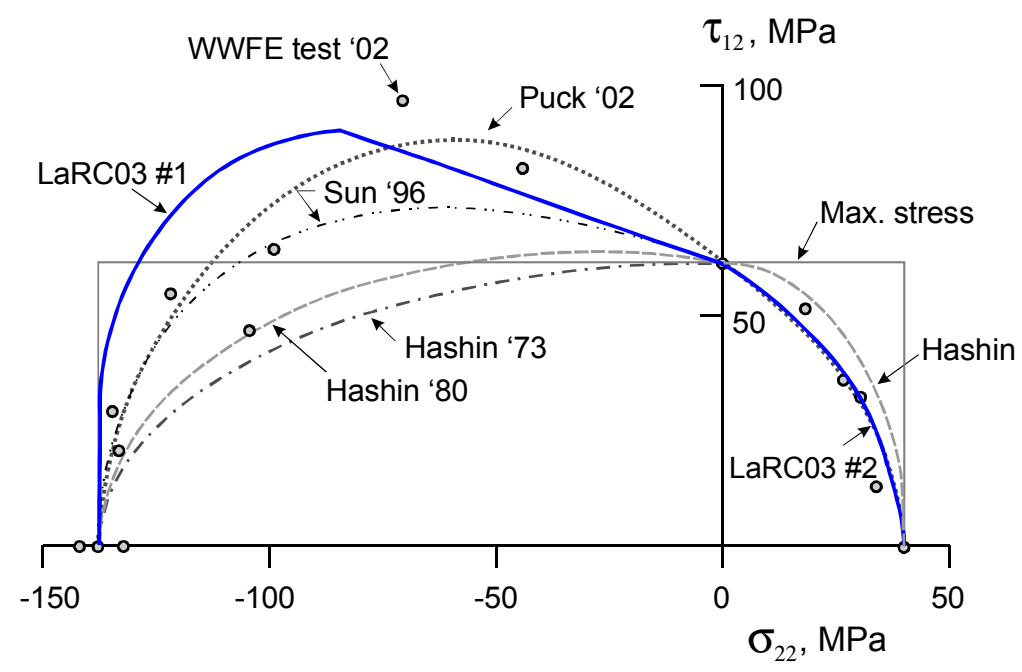

Figure 11. Failure envelopes and WWFE test data $^{2}$ for unidirectional composite E-Glass/LY556.

\section{Example 3. Cross-ply laminates}

Shuart ${ }^{47}$ studied the compression failure of $[ \pm \theta]_{\mathrm{s}}$ laminates and found that for $\theta<15^{\circ}$, the dominant failure mode in these laminates is interlaminar shearing; for $15^{\circ}<\theta<50^{\circ}$, it is in-plane matrix shearing; and for $\theta>50^{\circ}$, it is matrix compression. Fiber scissoring due to matrix material nonlinearity caused the switch in failure mode from in-plane matrix shearing to matrix compression failure at larger lamination angles. The material properties shown in Table 3 were used for the analysis. The angle $\alpha_{0}$ was assumed to be a typical $53^{\circ}$. For other lamination angles, the fracture angle was obtained by searching numerically for the angle that maximizes the failure criterion in Eq. 4. The in-situ shear strength did not need to be calculated since it is given by Shuart ${ }^{47}$ as $S_{i s}^{L}=95.1 \mathrm{MPa}$.

The results in Fig. 12 indicate that the predicted strengths using LaRC03 criteria correlate well with the experimental results. The compressive strength predicted using Hashin 1973 criteria is also shown in Fig. 
12. For $\theta<20^{\circ}$, the Hashin criteria result in an overprediction of the failure load because the criterion does not account for the effect of inplane shear on fiber failure. For lamination angles near $70^{\circ}$, the use of the Hashin criteria result in an underprediction of the failure load because the criteria do not account for the increase in shear strength caused by transverse compression. All of these effects are represented by the LaRC03 criteria, which results in a good correlation between the calculated and experimental values.

Table 3. Properties of AS4-3502 $2^{47}$ ( MPa)

\begin{tabular}{ccccccc}
\hline \hline $\boldsymbol{E}_{11}$ & $\boldsymbol{E}_{22}$ & $\boldsymbol{G}_{12}$ & $\boldsymbol{v}_{\boldsymbol{1 2}}$ & $\boldsymbol{X}^{\boldsymbol{C}}$ & $\boldsymbol{Y}^{\boldsymbol{C}}$ & $S_{i s}^{L}$ \\
\hline 127,600 & 11,300 & 6,00 & 0.278 & 1045 & 244 & 95.1 \\
\hline \hline
\end{tabular}

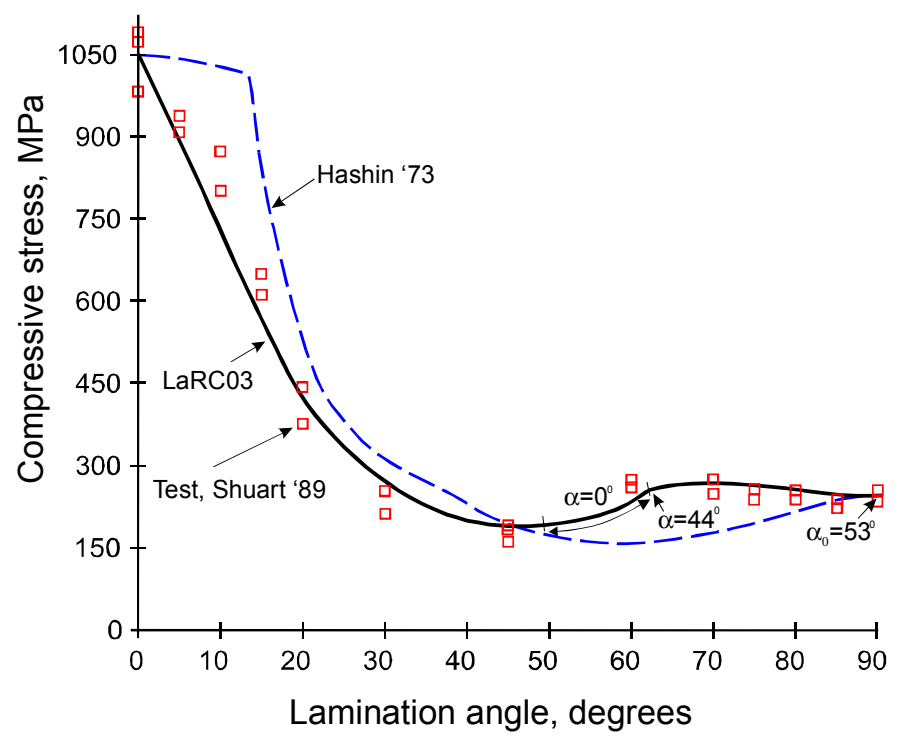

Figure 12. Compressive strength as a function of ply orientation for $[ \pm \theta]_{\mathrm{s}}$ AS4/3502 laminates.

\section{Concluding Remarks}

The results of the recently concluded World Wide Failure Exercise indicate that the existing knowledge on failure mechanisms needs further development. Many of the existing failure models could not predict the experimental response within a tolerable limit. In fact, differences of up to an order of magnitude between the predicted and experimental values were not uncommon. In this paper, a new set of six physically-based failure criteria devoid of empirical variables is proposed. The criteria for matrix and fiber compression failure are based on a Mohr-Coulomb interaction of the stresses associated with the plane of fracture. Failure envelopes for unidirectional laminates in the $\sigma_{11}-\sigma_{22}$ and $\sigma_{22}-\tau_{12}$ stress planes were calculated, as well as the compressive strength of cross-ply laminates. The predicted failure envelopes indicate good correlation with experimental results. The proposed criteria, referred to as LaRC03, represent a significant improvement over the commonly used Hashin criteria, especially in the cases of matrix or fiber failure in compression. 


\section{References}

1) Soden, P.D., Hinton, M.J., and Kaddour, A.S., "A Comparison of the Predictive Capabilities of Current Failure Theories for Composite Laminates," Composites Science and Technology, Vol. 58, No. 7, 1998, pp. 1225-1254.

2) Soden, P.D., Hinton, M.J., and Kaddour, A.S., "Biaxial Test Results for Strength and Deformation of a Range of E-Glass and Carbon Fibre Reinforced Composite Laminates: Failure Exercise Benchmark Data," Composites Science and Technology, Vol. 62, No. 12-13, 2002, pp. 1489-1514.

3) Hinton, M.J., Kaddour, A.S., and Soden, P.D., "A Comparison of the Predictive Capabilities of Current Failure Theories for Composite Laminates, Judged against Experimental Evidence," Composites Science and Technology, Vol. 62, No. 12-13, 2002, pp. 1725-1797.

4) Hinton, M.J., and Soden, P.D., "Predicting Failure in Composite Laminates: The Background to the Exercise," Composites Science and Technology, Vol. 58, No. 7, 1998, pp. 1001-1010.

5) Puck, A., and Schurmann, H., "Failure Analysis of FRP Laminates by Means of Physically Based Phenomenological Models," Composites Science and Technology, Vol. 58, No. 7, 1998, pp. 1045-1067.

6) Puck, A., and Schurmann, H., "Failure Analysis of FRP Laminates by Means of Physically Based Phenomenological Models," Composites Science and Technology, Vol. 62, No. 12-13, 2002, pp. 16331662.

7) Edge, E.C., "Stress-Based Grant-Sanders Method for Predicting Failure of Composite Laminates," Composites Science and Technology, Vol. 58, No. 7, 1998, pp. 1033-1041.

8) París, F., "A Study of Failure Criteria of Fibrous Composite Materials," NASA/CR-2001-210661, Hampton, VA, March 2001.

9) Hashin, Z., and Rotem, A., "A Fatigue Criterion for Fiber-Reinforced Materials," Journal of Composite Materials, Vol. 7, 1973, pp. 448-464.

10) Hashin, Z., "Failure Criteria for Unidirectional Fiber Composites," Journal of Applied Mechanics, Vol. 47, 1980, pp. 329-334.

11) Sun, C.T., Quinn, B.J., and Oplinger, D.W., "Comparative Evaluation of Failure Analysis Methods for Composite Laminates," DOT/FAA/AR-95/109, 1996.

12) Shahid, I., and Chang, F.-K., "An Accumulative Damage Model for Tensile and Shear Failures of Laminated Composite Plates," Journal of Composite Materials, Vol. 29, 1995, pp. 926-981.

13) Salençon, J., Handbook of Continuum Mechanics: General Concepts, Thermoelasticity, Springer, Berlin; New York, 2001.

14) Kawabata, S., "Strength of Epoxy Resin under Multiaxial Stress Field," Proceedings of the ICCM-IV, Tokyo, 1982, pp. 161-168.

15) Boehler, J.P., and Raclin, J., "Failure Criteria for Glass-Fiber Reinforced Composites under Confining Pressure," J. Struct. Mech., Vol. 13, No. 3 \& 4, 1985, pp. 371-392.

16) Taliercio, A., and Sagramoso, P., "Uniaxial Strength of Polymeric-Matrix Fibrous Composites Predicted through a Homogenization Approach," International Journal of Solids and Structures, Vol. 32, No. 14, 1995, pp. 2095-2123.

17) DiLandro, L., and Pegoraro, M., "Carbon Fibre-Thermoplastic Matrix Adhesion," Journal of Material Science, Vol. 22, 1987, pp. 1980-1986.

18) Larson, M.C., and Miles, H.F., "On the Effects of Friction, Roughness and Toughness on Interfacial Sliding in Brittle Composites," Mechanics of Materials, Vol. 27, No. 2, 1998, pp. 77-89.

19) Parvizi, A., Garrett, K., and Bailey, J., "Constrained Cracking in Glass Fibre-Reinforced Epoxy Cross-Ply Laminates," Journal of Material Science, Vol. 13, 1978, pp. 195-201.

20) Wang, A.S.D., "Fracture Mechanics of Sublaminate Cracks in Composite Materials," Composites Technology Review, Vol. 6, No. 2, 1984, pp. 45-62.

21) Tan, S.C., and Nuismer, R.J., "A Theory for Progressive Matrix Cracking in Composite Laminates," Journal of Composite Materials, Vol. 23, 1989, pp. 1029-1047. 
22) Talreja, R., "Transverse Cracking and Stiffness Reduction in Composite Laminates," Journal of Composite Materials, Vol. 19, 1985, pp. 355-375.

23) Allen, D.H., Harris, C.E., and Groves, S.E., "A Thermomechanical Constitutive Theory for Elastic Composites with Distributed Damage- I. Theoretical Development," International Journal of Solids and Structures, Vol. 23, No. 9, 1987, pp. 1301-1318.

24) Allen, D.H., Harris, C.E., and Groves, S.E., "A Thermomechanical Constitutive Theory for Elastic Composites with Distributed Damage- II. Application to Matrix Cracking in Laminated Composites," International Journal of Solids and Structures, Vol. 23, No. 9, 1987, pp. 1319-1338.

25) Talreja, R., Yalvac, S., Yats, L.D., and Wetters, D.G., "Transverse Cracking and Stiffness Reduction in Cross Ply Laminates of Different Matrix Toughness," Journal of Composite Materials, Vol. 26, No. 11, 1992, pp. 1644-1663.

26) Dvorak, G.J., and Laws, N., "Analysis of Progressive Matrix Cracking in Composite Laminates II. First Ply Failure," Journal of Composite Materials, Vol. 21, 1987, pp. 309-329.

27) Chang, F.-K., and Chen, M.-H., "The In Situ Ply Shear Strength Distributions in Graphite/Epoxy Laminated Composites," Journal of Composite Materials, Vol. 21, 1987, pp. 708-733.

28) Flaggs, D.L., and Kural, M.H., "Experimental Determination of the In Situ Transverse Lamina Strength in Graphite/Epoxy Laminates," Journal of Composite Materials, Vol. 16, 1982, pp. 103-116.

29) Laws, N., and Dvorak, G.J., "Progressive Transverse Cracking in Composite Laminates," Journal of Composite Materials, Vol. 22, 1988, pp. 900-919.

30) Hahn, H.T., and Johannesson, T., "Fracture of Unidirectional Composites: Theory and Applications," Mechanics of Composite Materials, G.J. Dvorak ed., AMD, 1983, pp. 135-142.

31) Liu, K.-S., and Tsai, S.W., "A Progressive Quadratic Failure Criterion for a Laminate," Composites Science and Technology, Vol. 58, No. 7, 1998, pp. 1023-1032.

32) Wu, E.M., and Reuter, R.C.J., "Crack Extension in Fiberglass Reinforced Plastics and a Critical Examination of the General Fracture Criterion," University of Illinois, Theor. and Appl. Mech. Report No. 275, Urbana-Champaign, 1965.

33) Leguillon, D., "Strength or Toughness? A Criterion for Crack Onset at a Notch," European Journal of Mechanics - A/Solids, Vol. 21, No. 1, 2002, pp. 61-72.

34) Tada, H., Paris, P., C., and Irwin, G.R., The Stress Analysis of Cracks Handbook, 3rd. ed, American Society of Mechanical Engineers, New York, 2000.

35) Fleck, N.A., and Liu, D., "Microbuckle Initiation from a Patch of Large Amplitude Fibre Waviness in a Composite under Compression and Bending," European Journal of Mechanics - A/Solids, Vol. 20, No. 1, 2001, pp. 23-37.

36) Soutis, C., Smith, F.C., and Matthews, F.L., "Predicting the Compressive Engineering Performance of Carbon Fibre-Reinforced Plastics," Composites Part A: Applied Science and Manufacturing, Vol. 31, No. 6, 2000, pp. 531-536.

37) Schultheisz, C.R., and Waas, A.M., "Compressive Failure of Composites, Part 1: Testing and Micromechanical Theories," Progress in Aerospace Sciences, Vol. 32, 1996, pp. 1-42.

38) Argon, A.S., Fracture of Composites, Treatise of Materials Science and Technology, Vol. 1, Academic Press, New York, 1972.

39) Budiansky, B., Fleck, N.A., and Amazigo, J.C., "On Kink-Band Propagation in Fiber Composites," Journal of the Mechanics and Physics of Solids, Vol. 46, No. 9, 1998, pp. 1637-1653.

40) Berg, C.A., and Salama, M., "Fatigue of Graphite Fibre-Reinforced Epoxy in Compression," Fibre Science and Technology, Vol. 6, No. 2, 1973, pp. 79-118.

41) Schapery, R.A., "Prediction of Compressive Strength and Kink Bands in Composites Using a Work Potential," International Journal of Solids and Structures, Vol. 32, No. 6-7, 1995, pp. 739-765.

42) Potter, D.S., Gupta, V., and Hauert, S., "Effects of Specimen Size and Sample Aspect Ratio on the Compressive Strength of Graphite/Epoxy Laminates," Composites Science and Technology, Vol. 60, No. 12-13, 2000, pp. 2525-2538. 
43) Waas, A.M., and Schultheisz, C.R., "Compressive Failure of Composites, Part II: Experimental Studies," Progress in Aerospace Sciences, Vol. 32, No. 1, 1996, pp. 43-78.

44) Wronski, A.S., and Parry, T.V., "Compressive Failure and Kinking in Uniaxially Aligned Glass-Resin Composite under Superposed Hydrostatic Pressure," Journal of Material Science, Vol. 17, 1982, pp. 36563662.

45) Sigley, R.H., Wronski, A.S., and Parry, T.V., "Axial Compressive Failure of Glass-Fibre Polyester Composites under Superposed Hydrostatic Pressure: Influence of Fibre Bundle Size," Composite Science and Technology, Vol. 43, 1992, pp. 171-183.

46) Soden, P.D., Hinton, M.J., and Kaddour, A.S., "Lamina Properties, Lay-up Configurations and Loading Conditions for a Range of Fibre-Reinforced Composite Laminates," Composites Science and Technology, Vol. 58, No. 7, 1998, pp. 1011-1022.

47) Shuart, M.J., "Failure of Compression-Loaded Multidirectional Composite Laminates," AIAA Journal, Vol. 27, No. 9, 1989, pp. 1274-1279. 
Appendix. Summary of LaRC03 Failure Criteria

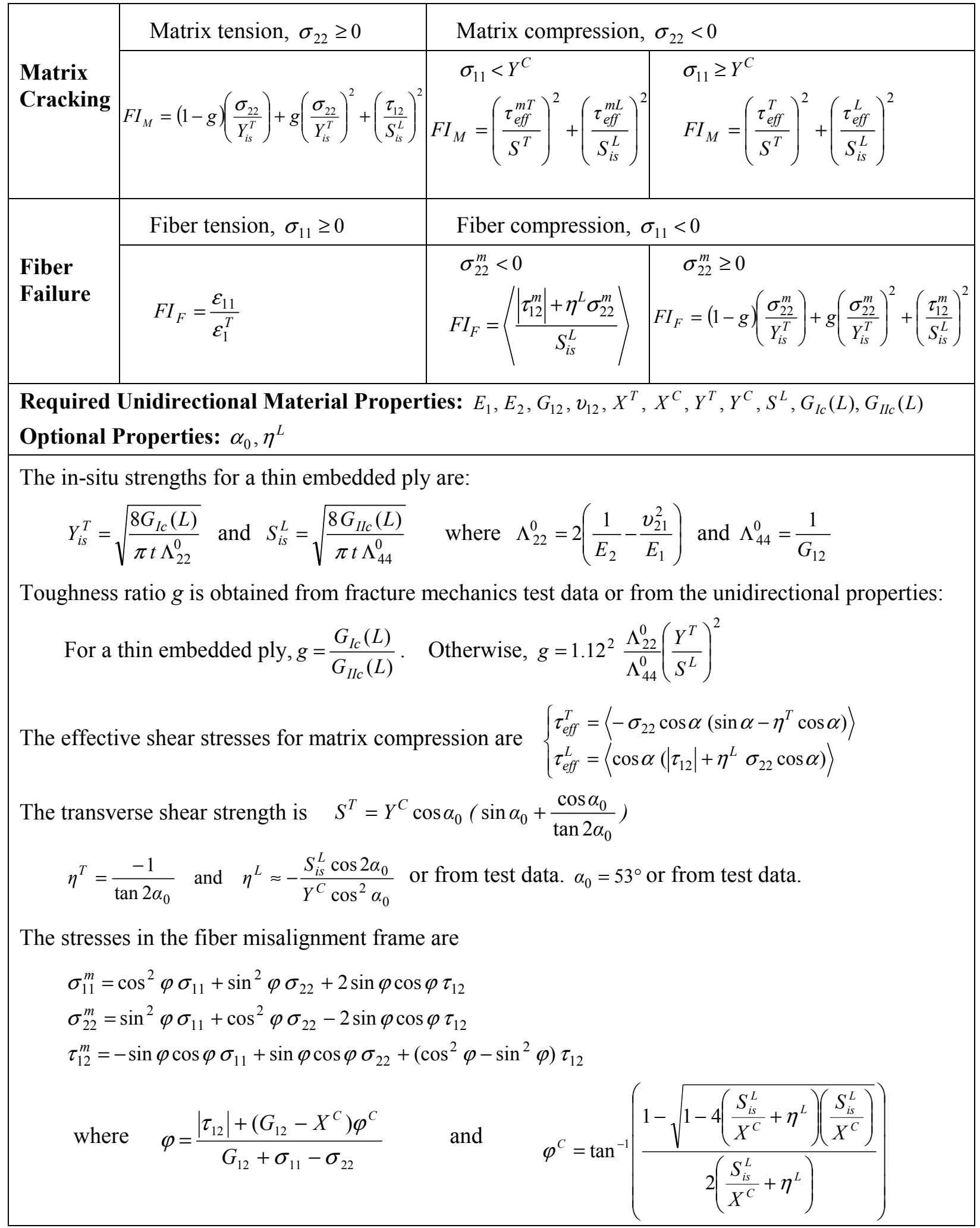




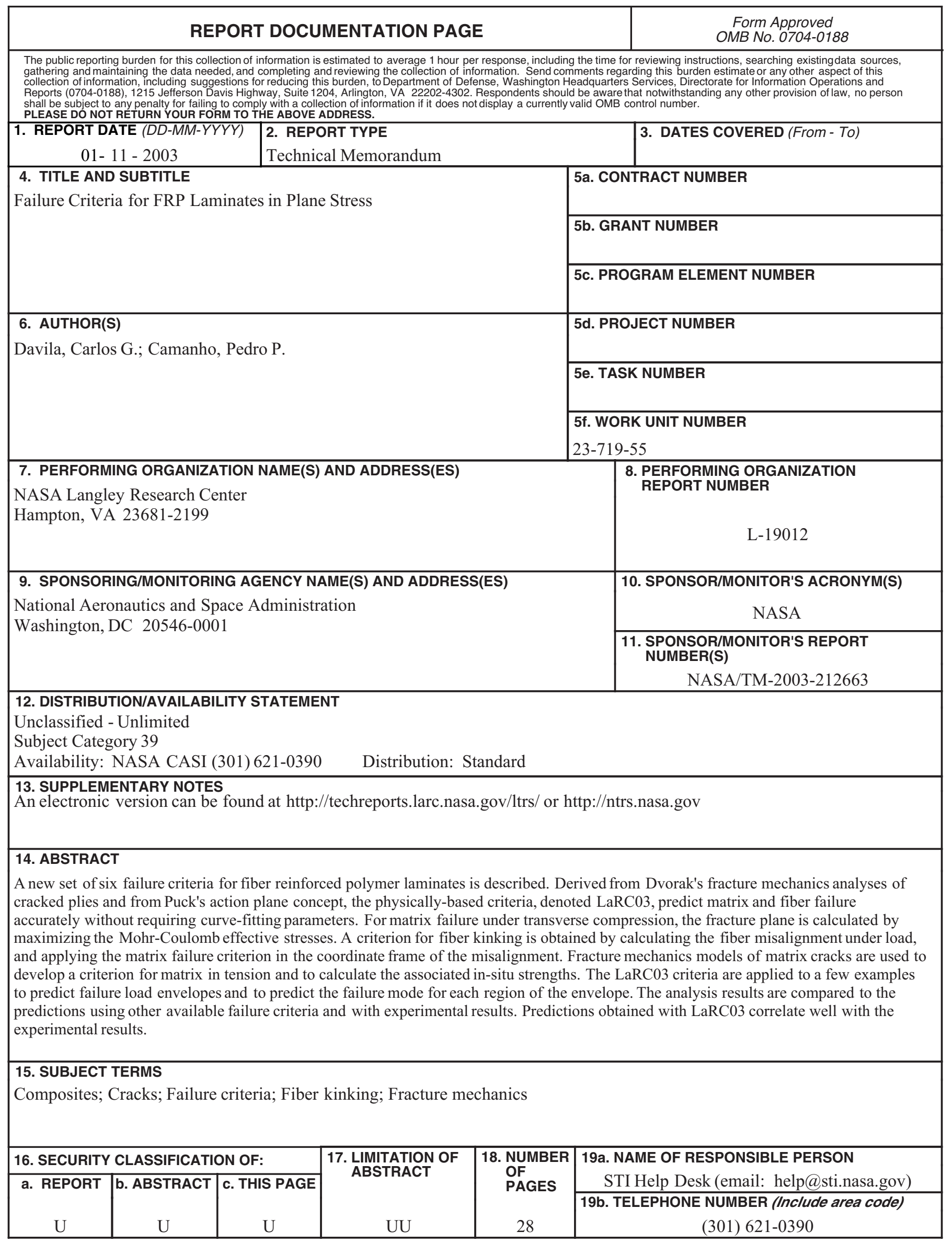

